\title{
O ESGOTAMENTO NA CONTEMPORANEIDADE
}

Resenha de: HAN, Byung-Chul. Sociedade do cansaço. Tradução de Ênio Paulo Giachini, 1. ed. Petrópolis, RJ: Vozes, 2015, 78p.

\author{
Bruno Cesar Mira ${ }^{1}$ \\ http://lattes.cnpq.br/3199824820713711 \\ https://orcid.org/0000-0001-6058-8668
}

Recebido em 06 de março de 2019.

Aprovado em 17 de março de 2020.

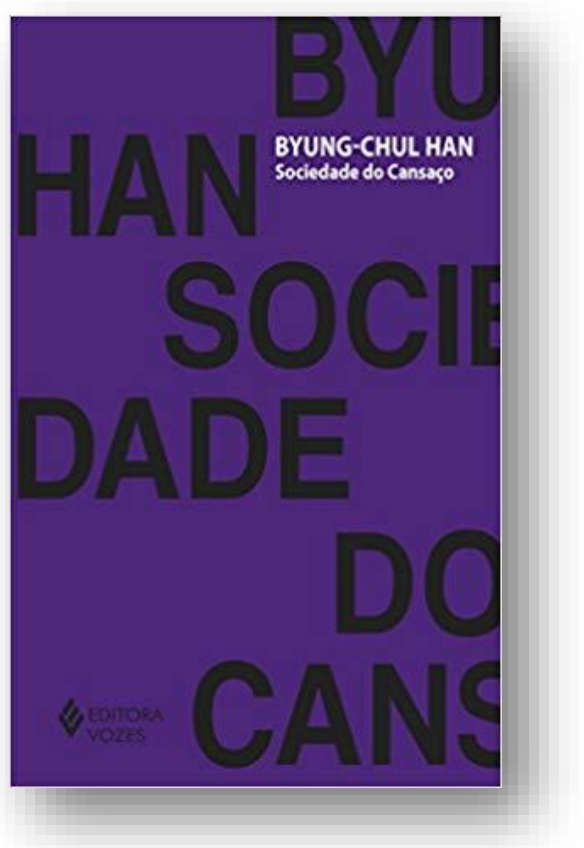

No ensaio $A$ sociedade do cansaço, o filósofo sul coreano, radicado na Alemanha, Byung-Chul Han parte das teorizações de outros pensadores para compreender as nuances da condição do homem moderno. Pensadores como Michel Foucault, Gilles Deleuze, Nietzsche, Jean Baudrillard, Giorgio Aganbem e Hannah Arendt fundamentam a reflexão do autor.

No primeiro capitulo intitulado Violência neuronal, o filósofo faz um paralelo entre o modelo sociopolítico do séc. XX embasado na lógica imunológica e o modelo do mundo atual que tem como cerne os diferentes tipos de positivações. Na era imunológica, é possível que os limites estavam circunscritos como: dentro-fora, inimigo-amigo, ataque-defesa. A questão evolvia se imunizar frente as designações daquilo que era considerado estranho. Entretanto, no mundo atual cedem lugar a novos quadros de sofrimentos tais como: síndrome de hiperatividade (Tdah), transtorno de personalidade limítrofe (TPL), síndrome de burnout (SB). Segundo o autor, essas doenças decorrem da nova lógica social econômica embasada na positivação do sujeito. Nesta lógica exploratória, o outro - estranho - não estaria mais nomeado através do exterior como algo a ser evitado. A positividade do "faça você mesmo" e "você pode e merece" não possui a negatividade presente pela alteridade, mas sim, incitações exaustivas causando a violência neuronal. Nas palavras do autor: "A violência neuronal não parte mais de uma negatividade estranha ao sistema, é antes uma violência sistêmica, isto é, uma violência imanente ao sistema. " (p. 20).

Em além da sociedade disciplinar, segundo capítulo do livro, Han delineia os limites do modelo disciplinar na obra de Michel Foucault. Na sociedade disciplinar, a estrutura acontece através da negatividade. Porém, atualmente, as disciplinas das instituições como: hospitais, presídios,

${ }^{1}$ Graduado em Ciências Sociais pelo Instituto Federal do Triângulo Mineiro (IFTM), campus Uberaba-MG, e em História pela Faculdade de Filosofia Ciências e Letras de Ituverava (FFCL). Possui Pós-Graduação lato sensu em: Formação de Professores para a Educação de Jovens e Adultos - PROEJA pelo IFTM de Uberaba-MG. Atualmente, é Mestrando em Educação na Universidade Federal do Triângulo Mineiro (UFTM), campus Uberaba-MG. E-mail: brunomira3@hotmail.com. 
quarteis, cede lugar a [...]" uma sociedade de academias fitness, prédios de escritórios, bancos, aeroportos, shopping centers e laboratórios de genética" (p. 22)

A disciplina pautada pela lógica do dever não acabou. Pelo contrário, somou-se ao crivo da sociedade do desempenho, onde o sujeito é o empresário de si mesmo. Na sociedade do desempenho, o verbo nodal é o poder, que se estabelece a partir da liberdade do sujeito. Os discursos de iniciativa, projeção e motivação são os elementos de adaptação ao modelo de desempenho. O resultado segundo o autor, seria a implosão neuronal frente ao modelo em que a liberdade é explorada a partir do indivíduo consigo mesmo, tendo como consequência os estados depressivos "O depressivo é o inválido dessa guerra internalizada. A depressão é o adoecimento de uma sociedade que sofre sob o excesso de positividade” (HAN, 2015, p.29).

Podemos fazer um paralelo com os dizeres de Foucault no curso O nascimento da biopolitica de 1978-1979, onde o autor designa o processo de subjetivação do modelo neoliberal. "O homo oeconomicus que se quer reconstituir não é o homem da troca, não é o homem consumidor, é o homem da empresa e da produção" (FOUCAULT, 2004, p. 201). Assim, por conseguinte, o adoecimento do sujeito contemporâneo frente ao regime de positividade, leva o mesmo apenas a se culpar dentro deste regimento normativo. Esse quadro desencadeia a culpa por não alcançar os preceitos impostos no modelo neoliberal de autogestão da liberdade. A responsabilidade é apenas no próprio indivíduo, que não soube administrar sua "liberdade", visto que o mote da lógica neoliberal é o autogoverno do sujeito enquanto empresa.

Outra capacidade que o sujeito do desempenho perde com o incessante fluxo de informações ao qual está imerso é a capacidade do Tédio profundo, título do terceiro capítulo. Contrastando com a vida contemplativa que o tédio requer, Han reflete sobre a técnica multitarefa (multitastasking) presente na vida selvagem de muitos animais que precisam ficar sempre à espreita dividindo sua atenção entre mastigar e a atenção para não se tornar caça (HAN, 2015).

Segundo o autor, estamos perdendo os recursos para a vida contemplativa que requer um profundo investimento de atenção do sujeito. No lugar deste tédio profundo está a hiperatenção (byperattention) "Essa atenção dispersa se caracteriza por uma rápida mudança de foco entre diversas atividades, fontes informativas e processos. E visto que ele tem uma tolerância bem pequena ao tédio" (HAN, 2015, p.33). O filósofo recorre as reflexões de Walter Benjamin sobre a necessidade do tédio enquanto forma de escutar que requer do sujeito atenção profunda, diferente da hiperatenção que dispersa o sujeito de uma atividade para outra. O homem moderno não suporta o passar do tempo no tédio. Nas palavras do filósofo Blaise Pascal: "nada é mais insuportável para o homem do que estar em pleno repouso, sem paixões, sem afazeres, sem divertimento, sem aplicação" (PASCAL, 2005, p.268). Esse esvaziamento que o tédio tenciona em um modelo de tempo diferente da hiperatenção torna-se insuportável para o homem moderno que sofre um excesso de estímulos sensórias, considerando estes últimos como a única coisa realmente significativa (SVENDSEN, 2006).

No quarto capítulo, a partir do conceito de vida activa de Hannah Arendt, o autor explora o agir do homem na modernidade que passou a ser investido enquanto animal laborans, ficando sua vida reduzida em sua atividade enquanto trabalhador. No entanto na pós-modernidade da sociedade do desempenho, o animal laborans não destitui o seu ego. Pelo contrário, "o animal laborans pós-moderno é provido do ego ao ponto de quase dilacerar-se. Ele pode ser tudo menos ser passivo". (HAN, 2015, p.43).

Han vai abordar com maior densidade a exposição do ego na obra: a sociedade da transparência. Nesse livro, o autor discute o conceito transparência, na qual o rompimento entre público 
e aquilo até então considerado privado desaparece na busca por autoafirmação nos meios digitais. Outro ponto abordado no capítulo é o processo de desnarrativação (Entnarrativisierving), que consiste na procura de alguma substancialidade ou fé em qualquer princípio que estabeleça algum tipo de apoio consistente para o sujeito com qualquer tipo de narratividade. Como consequência desta procura por alguma narrativa que perdure, o nervosismo e as inquietações seriam os sintomas causados por essa incessante busca.

Outro tema abordado no capítulo é o conceito de Homo sacer no direito romano arcaico indica o indivíduo que cometeu um delito, que pode ser sacrificável sem qualquer tipo de penalização. As reflexões sobre o homo sacer presentes na obra do filosofo italiano Giorgio Aganben traça um paralelo com a modernidade e com os campos de concentração nazista em que a figura do homo sacer é a regra. De que forma opera esse conceito na sociedade do desempenho? Segundo Han (2015, p.46) "todavia eles têm a especificidade de serem mortos, mas de serem absolutamente não passiveis de serem mortos. São como mortos-vivos. " A auto coerção análogo aos critérios do desempenho faz o sujeito se auto infligir a disciplina, o que coloca como senhor e escravo, vítima e algoz ao mesmo tempo. Não é necessário campo de concentração para reduzir o ser humano apenas reduzido a vida nua ${ }^{2}$, como discutido por Aganben (2012).

Nietzsche, no livro o crepúsculo dos ídolos expõe as diretrizes necessárias para uma vida ativa. Entre os elementos exposto pelo autor estão o aprender a pensar, a ler, a falar e a escrever. No quinto capítulo pedagogia do ver. Han reflete as nuances que o sujeito do desempenho enfrenta para uma vida ativa a partir do diálogo com Nietzsche. Para a vida contemplativa segue como parâmetro o olhar parado e lento, diferente da sociedade do desempenho, que coloca a interrupção como negatividade tendo em conta que está hesitação segue como necessária para educar os sentidos para a vida contemplativa. Han faz uma analogia entre a ira e a irritação, sendo que a primeira necessita da interrupção do fluxo do movimento. "A ira é uma capacidade que está em condições de interromper um estado, e fazer com que se inicie um novo estado" (HAN, 2015, 54) A segunda é cumulativa, ou seja, ela não necessita de mudança, seu sintoma é imanente ao sujeito frente ao seu contexto ininterrupto. Outro ponto abordado pelo autor são as duas formas de potências positiva e negativa. Na positiva estamos presos ao objeto e estímulos para a percepção sendo a hiperatividade uma imperiosa e unilateral fenômeno da potência positiva (HAN, 2015). A potência negativa impõe o estacionamento, o não-fazer, indispensável para a contemplação da vida ativa e considerada uma desvantagem frente ao imperativo da potência positiva.

Em 1853, Herman Melville publica sua pequena novela Bartleby o escriturário. Nessa obra Melville apresenta a atmosfera cinzenta de um escritório em Nova York onde o escriturário Bartleby trabalha totalmente apático e esvaziado de todos os sentimentos sendo a frase "I would Prefer not to" proferida pelo personagem ao longo da história. No sexto capítulo $O$ caso Bartleby acompanhamos a reflexão do autor a respeito dos sintomas do personagem como elementos causados pelo excesso de positivações. Han se contrapõem a interpretação de Aganbem, que eleva o personagem com um ser que resistiu a todo esvaziamento, elevando sua potência frente ao nada como elemento de criação. O autor converge do ponto de vista de Aganbem [...] "não é uma história de "des-criação" (Ent-Schopfung), mas uma história de esgotamento (Erschopfung)". (HAN, 2015, p.68).

No último capítulo, que tem o mesmo título do livro, sociedade do cansaço, Han tem como

2 [...] vida nua, isto é, a vida matável e insacrificável do homem sacer. (AGANBEN, 2012, P.16) 
ponto de partida o conceito de doping que seria substituído por neuro-enchancement tendo como função aumentar o desempenho. $\mathrm{O}$ autor ainda cita o caso de médicos que poderiam operar mais pessoas e com uma concentração melhorada (HAN, 2015). A sociedade do cansaço é analisada como uma sociedade que perdeu a negatividade. "O excesso da elevação do desempenho leva a um infarto da alma” (HAN, 2015, p.71) Esse infarto da alma seria o cansaço do indivíduo moderno.

Em outro momento, o autor dialoga com o artigo versuch yber die mudigkeit (ensaio sobre o cansaço) de Peter Handke, que explora as diferentes nuances do cansaço. De acordo com Handke, há dois tipos de cansaço, um seria aquele que impossibilitaria o sujeito de falar com a alma é o cansaço calado. No outro polo está o cansaço que possibilita tocar no outro e ser tocado. Neste último tipo de cansaço profundo o sujeito seria capaz através da desaceleração reconstituir sua admiração ao mundo como diz o autor. Han termina sua obra refletindo sobre a segunda tipologia de cansaço e concluindo: "O cansaço se dá o compasso ao indivíduo disperso [...] É uma sociedade dos cansados em sentido específico [...] fosse sinônimo de sociedade futura, a sociedade por vir poderia chamar-se então sociedade do cansaço" (p.78).

\section{REFERÊNCIAS}

AGANBEN, Giorgio. Homo sacer: poder soberano e a vida nua I. 2.ed. Belo Horizonte: Editora UFMG, 2012.

FOUCAULT, Michel. O nascimento da biopolítica. São Paulo: Martins Fontes, 2008.

HAN, Byung-Chul. Sociedade da transparência. Rio de Janeiro: Vozes, 2017.

PASCAL, Blaise. Pensamentos. 2.ed. São Paulo: Martins Fontes, 2005.

SVENDSEN, Lars. Filosofia do tédio. Rio de Janeiro: Jorge ZAHAR Editor, 2006. 